\title{
EDUCAÇ̃̃O EM CIÊNCIAS E MATEMÁTICA: A FUNÇ̃̃O DA LINGUAGEM NO CONTEXTO DA SALA DE AULA
}

\author{
Rosana Maria Luvezute Kripka* \\ Everton Luís Luz de Quadros** \\ Rosane Alves Pretto de Oliveira*** \\ Maurivan Güntzel Ramos***
}

RESUMO: Apresenta-se uma análise sobre entendimentos de professores de Matemática, Ciências e Pedagogia sobre a função da linguagem no contexto da sala de aula. A pesquisa é qualitativa, com vistas a construir respostas à seguinte questão: Como os professores de Matemática, Ciências e Pedagogia, participantes da pesquisa, entendem a função da linguagem em sala de aula? Participaram vinte professores da educação básica ou ensino superior, que responderam a um questionário para a constituição de dados. As respostas foram tratadas por meio da Análise Textual Discursiva. Concluiu-se que a função da linguagem é entendida pelos professores como: meio de aprendizagem; meio de comunicação e como meio para formação, que remetem às compreensões consideradas sobre linguagem disponíveis na literatura, mas não na totalidade das respostas. A falta de reflexão e pouca valorização da linguagem no contexto da sala de aula podem fazer com que os professores não a explorem como um meio para potencializar o desenvolvimento de competências.

Palavras-chave: Linguagem. Aprendizagem. Formação.

\section{EDUCACIÓN EN CIENCIAS Y MATEMÁTICAS: LA FUNCIÓN DEL LENGUAJE EN EL CONTEXTO DE CLASE}

RESUMEN: Se presenta un análisis acerca de entendimientos de profesores de Matemáticas, Ciencias y Pedagogía a respecto de la función del lenguaje en el contexto de clase. La investigación es cualitativa, con el objetivo de construir respuestas a la siguiente cuestión: ¿Cómo los profesores de Matemáticas, Ciencias y Pedagogía, participantes de la investigación, comprenden la función del lenguaje en clase? Participaron veinte profesores de la educación primaria y secundaria o educación superior, que contestaron a un cuestionario para constitución de datos. Se trataron las respuestas por medio del Análisis Textual Discursivo. Se concluyó que la función del lenguaje es comprendida por profesores como: medio de aprendizaje; medio de comunicación y como medio para la formación, que se refieren a las comprensiones consideradas acerca del lenguaje disponibles en la literatura, pero no en la totalidad de las respuestas. La falta de reflexión y la poca valoración del lenguaje en el contexto de clase

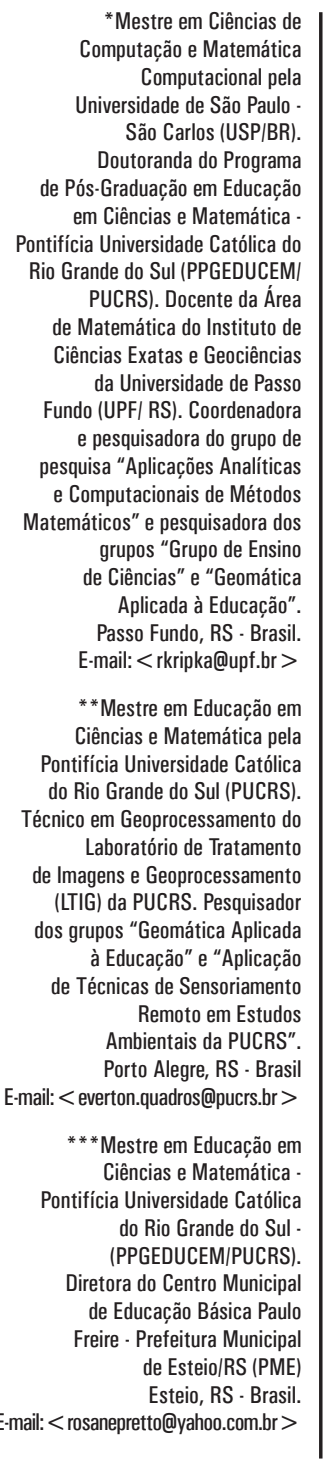


pueden ocasionar que los profesores no lo exploten como un medio para potenciar el desarrollo de competencias.

Palabras clave: Lenguaje. Aprendizaje. Formación.

SCIENCE AND MATHEMATICS EDUCATION: THE FUNCTION OF LANGUAGE IN THE CLASSROOM CONTEXT

ABSTRACT: The paper presents an analysis of understandings of Mathematics teachers, Science and Pedagogy about the function of language in the classroom context. The research is qualitative and aims to answer: How Science, Mathematics and Pedagogical teachers, that have participated of the research, understands the function of language in the classroom? Twenty basic or higher education teachers have attended and answered a questionnaire for the constitution of data. Responses were treated by Textual Analysis of Discourse. We have concluded that the function of language is understood by the teachers as: a means of learning; means of communication and as a means of formation, which refer to the understandings considered on language available in the literature, but not in the totality of the answers. The lack of reflection and little appreciation of language in the classroom context can contribute to the teachers do not use it as a means for enhance the development of competencies.

Keywords: Language. Learning. Formation.

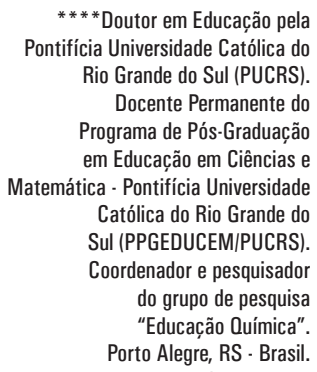

E-mail:<mgramos@pucrs.br > 


\section{INTRODUÇÃO}

O surgimento da linguagem impulsionou a evolução humana, tanto em termos de conhecimentos práticos, quanto em conhecimentos científicos, pois as informações puderam ser armazenadas e comunicadas para as futuras gerações, possibilitando ressignificação, reconstrução e ampliação de conhecimentos.

Wells (2001) afirma que, refletindo sobre o início da história humana, é possível perceber que existem diferentes modos de conhecer. Destaca que, na constituição desses modos houve a necessidade da interação social, sendo necessária a mediação por alguma forma de comunicação simbólica. O autor refere que, desde o início dos tempos, foram criadas interpretações externas que conservavam o conhecimento cultural, como pinturas rupestres ou esculturas religiosas. Mas foi a invenção da escrita, baseada em linguagem, que se constituiu no avanço mais importante do conhecimento. A escrita facilitou a recuperação dos significados repassados pela interação falada e possibilitou sua divulgação para leitores, em diferentes épocas e lugares. A escrita proporcionou a base para uma nova forma de construção do conhecimento mediada pelo texto. Além disso, hoje em dia, uma diferença importante a ser considerada é que temos acesso a diferentes fontes de informação por meio de artefatos simbólicos, tais como mapas, manuais de instrução ou obras de referência literária, que atuam como mediadores em nossas ações. Nossos antepassados dependiam apenas de suas lembranças quando sentiam necessidade de aplicá-las novamente em outro contexto de seu cotidiano.

Desse modo, pela importância da linguagem, na construção de conhecimentos sociais e culturais e, em particular, em processos de ensino e de aprendizagem, acredita-se ser importante compreender como os professores entendem sua função no contexto da sala de aula. Assim, com a presente investigação buscou-se responder à seguinte pergunta: Como os professores de Matemática, Ciências e Pedagogia, participantes da pesquisa, entendem a função da linguagem em sala de aula?

\section{PRESSUPOSTOS DA INVESTIGAC̣ÃO}

As contribuições científicas da linguística e semiótica compõem os pressupostos desta investigação. A seguir, são elencados alguns autores que contribuem para a compreensão da linguagem no contexto da sala de aula.

Apesar de apresentarem diferentes interesses em suas pesquisas, o psicólogo Lev Semenovich Vygotsky (1998), o linguista Gordon Wells (2001) e o linguista Michael Alexander Kirkwood Halliday (1993), identificaram que no âmbito da ontogenia, o desenvolvimento da linguagem é um recurso importante para a aprendizagem humana e para o desenvolvimento cognitivo.

Para Wells (2001) o objetivo principal da pesquisa de Vygotsky foi a explicação do funcionamento mental do indivíduo, que ocorre em função da interação social, da cultura e dos discursos envolvidos, com foco na dimensão intraorgânica. Entretanto, Wells (ibid.) considera que o objetivo principal da pesquisa para Halliday é a explicação da natureza e da organização da linguagem como recurso para a vida em sociedade, baseado em relações pessoais com orientação essencialmente social e funcional, com foco na dimensão interorgânica. 
Tanto Vygotsky quanto Halliday entendem que a linguagem se constitui em um meio para se alcançar objetivos da vida em sociedade. Nesse sentido, Wells (2001) afirma que ambos adotam um enfoque genético, por acreditarem que o melhor modo para compreenderem o estado atual do desenvolvimento humano consiste em compreender as fases do desenvolvimento que o precederam, visando a estudar as manifestações da linguagem como ferramenta na aprendizagem.

A teoria de aprendizagem sócio-histórica, desenvolvida por Vygotsky (1998), tem como fundamento a linguagem, pois ele considera que, em todos os grupos humanos, a linguagem é um sistema simbólico básico. Compreender como se dá o desenvolvimento do pensamento e da linguagem, bem como, as relações existentes entre eles foram questões centrais de sua pesquisa. Para o autor "[...] o desenvolvimento do pensamento é determinado pela linguagem, isto é, pelos instrumentos linguísticos do pensamento e pela experiência sócio-cultural da criança. [...]" (VYGOTSKY, 1998, p. 62).

Segundo Oliveira (1993), Vygotsky identifica duas funções básicas da linguagem. A primeira função seria de "intercâmbio social", que possibilita a comunicação com seus semelhantes por meio dos sistemas de linguagem. A autora afirma que, para Vygotsky, foi a necessidade de comunicação que impulsionou inicialmente o desenvolvimento da linguagem, sendo posteriormente aprimorada pela criação dos signos, para sua sofisticação. A segunda função da linguagem é a do "pensamento generalizante", ou seja, aquela que possibilita a constituição de categorias conceituais, por meio de classificações, ordenações e agrupamentos. Para a autora:

É essa função de pensamento generalizante que torna a linguagem um instrumento de pensamento: a linguagem fornece os conceitos e as formas de organização do real que constituem a mediação entre o sujeito e o objeto de conhecimento. A compreensão das relações entre pensamento e linguagem é, pois, essencial para a compreensão do funcionamento psicológico do ser humano. (OLIVEIRA, 1993, p. 43)

Vygotsky (1998) considera a linguagem como "o instrumento dos instrumentos", pois ela funciona como mediadora em atividades sociais e também como instrumento mediador de atividades mentais, associadas ao discurso interno, relativo à fala interior, sendo esse o foco de seus estudos para a compreensão do funcionamento mental humano. Vygotsky concebe a linguagem como "instrumento semiótico", com a função de mediação, entre o participante e o objeto do conhecimento por meio da construção de signos.

$\mathrm{Na}$ teoria de aprendizagem baseada na linguagem, proposta por Halliday (1993), o autor destaca a importância da linguagem na construção do conhecimento ao salientar que: "[...]; a linguagem é a condição essencial do conhecer, é o processo pelo qual a experiência se converte em conhecimento." (HALLIDAY, 1993, p. 94, tradução nossa).

Halliday (1978) concebe a linguagem como "semiótica social", inserida num contexto sociocultural, defendendo que a realidade social (ou uma cultura) é um edifício de significados, ou seja, um constructo semiótico. Como linguista, destaca a conduta linguística e seus fins para a vida social, onde um dos mais importantes fins seria a manipulação e a construção do conhecimento. Para Halliday (1978, p. 2, tradução 
nossa): "[...] Mediante seus atos cotidianos de significados, as pessoas representam a estrutura social, afirmando suas próprias condições e papéis e estabelecendo e transmitindo sistemas de valores compartilhados e de conhecimento.”.

$\mathrm{O}$ autor ao se referir ao ambiente ecológico e social, sugere duas funções básicas da linguagem: "[...] dar sentido à nossa experiência e atuar em nossas relações sociais. [...]" (HALLIDAY, MATTHIESSEN, 2004, p. 29, tradução nossa).

$\mathrm{O}$ autor, ao abordar sobre as funções da linguagem, usa o termo metafunção para caracterizá-las, argumentando que, geralmente, o termo função refere-se apenas ao propósito do uso da linguagem e não teria significado ao ser usado para a análise da própria linguagem. Indica que a organização da linguagem se deve à evolução de suas funções pela espécie humana. Assim esclarece que: “[...] O termo metafunção foi adotado para sugerir que a função era um componente integral dentro da teoria geral [...]." (HALLIDAY, MATTHIESSEN, 2004, p. 31, tradução nossa).

Assim, considera a existência de três metafunções da linguagem: metafunção ideacional: referindo-se ao modo como as pessoas, por meio de suas experiências, idealizam, estruturam e se expressam sobre a realidade percebida; metafunção interpessoal: usada para expressar os significados de ações percebidas em relações sociais e (iii) metafunção textual: referindo-se ao uso da linguagem para expressão conteúdo organizado de acordo com o ‘contexto’ da situação. (HALLIDAY, 1985).

Segundo o autor:

[...] o aspecto mais importante do princípio metafuncional, para a teoria da aprendizagem, é que na linguagem (diferentemente da protolinguagem) é a combinação do experiencial e do interpessoal que constitui um ato de significado. Todo o significado - e, portanto, todo o aprendizado - é ao mesmo tempo ação e reflexão.” (HALLIDAY,1993, p.101, tradução nossa)

Embora não pretenda estabelecer distinção entre comunicar e pensar, as proposições de Halliday (Ibid.) integram uma teoria de reflexão sobre a experiência, na qual reflexão é entendida como "[...] construção linguística do conteúdo da experiência” (WELLS, 2001, p. 47, tradução nossa).

Wells (idem) também afirma que apesar de existirem diferenças nos interesses de suas pesquisas, Vygotsky e Halliday se interessaram por investigar o papel da linguagem para o desenvolvimento cognitivo do indivíduo, como membro de uma cultura em particular.

Assim, esses autores referem sobre a importância da aprendizagem da linguagem por meio das interações sociais, para a apropriação da cultura. Tal compreensão pressupõe que no emprego de instrumentos semióticos, como meios de comunicação, especialmente no caso da linguagem, as pessoas constroem/expressam suas culturas e as transmitem para gerações futuras, em interações cotidianas.

Destacam-se também as contribuições do antropólogo sociocultural James V. Wertsch (1999), relacionadas ao ensino de Ciências, relativas à ideia da aproximação sociocultural à mente. O pesquisador propõe compreender o fenômeno da mente humana, por uma abordagem sociocultural, em que considera o meio social e material decisivos nesse processo. Em seus princípios teóricos, propõe compreender o funcionamento humano por meio da "ação mediada" em "processos mentais", em "contextos socioculturais" particulares. Wertsch (1999) 
entende por "ação mediada" uma ação humana entre participantes, denominados de "agentes ativos", e meios mediacionais, denominados de "ferramentas culturais", as quais estão disponibilizadas aos agentes, em determinado espaço/tempo histórico específico. Afirma que, na ação humana existe uma tensão irredutível entre agentes e ferramentas culturais, que chama de "Indivíduos-atuando-comferramentas-culturais" (Ibid.). O autor considera como unidade de análise a relação dinâmica entre processos mentais e o contexto sociocultural que ocorrem por meio de ações mediadas por ferramentas culturais. Também, considera que as ferramentas culturais estão associadas ao poder e à autoridade, o que remete à importância da linguagem como meio mediacional, atuando como instrumento tanto na comunicação, como no desenvolvimento do pensamento humano.

A compreensão da linguagem é ampliada quando se considera as contemporâneas contribuições da semiótica relacionadas com a construção do conhecimento. Nesse sentido, consideram-se os estudos realizados pelo Linguista Charles S. Peirce (1839-1914) sobre a Teoria Cognitiva Semiótica, também conhecida por Teoria Geral dos Signos (PEIRCE, 1972).

Segundo Santaella (2005), a Semiótica Peirceana se relaciona à ciência que tem por objetivo a investigação sobre toda e qualquer linguagem, seja ela verbal ou não verbal, e sobre seus signos, reais ou abstratos, na busca da compreensão dos fenômenos que se apresentam na vida do ser humano, ao longo da sua existência. Nesse sentido é importante salientar que a linguagem (oral ou escrita) não se reduz à linguística, mas é compreendida como um fenômeno complexo a partir da ciência semiótica, pois

Cumpre notar que a ilusória exclusividade da língua, como forma de linguagem e meio de comunicação privilegiados, é muito intensamente devida a um condicionamento histórico que nos levou à crença de que as únicas formas de conhecimento, de saber e de interpretação do mundo são aquelas veiculadas pela língua, na sua manifestação como linguagem verbal oral ou escrita. (SANTAELLA, 2005, p. 2)

Esse entendimento encaminha a uma leitura complexa de mundo. Complexo (ou complexus) é aqui compreendido como aquilo que é tecido junto (MORIN, 2003). Nesse sentido, as contribuições da semiótica possibilitam ampliar a visão sobre a linguagem, dando-lhe um sentido mais abrangente de suas funções em relação ao processo de construção cultural, que ocorre nas interações em sala de aula ao (re)afirmar ou (re)construir conhecimentos, hábitos ou ideologias.

Pelo exposto, neste trabalho analisa-se os entendimentos de professores de Matemática, Ciências e Pedagogia sobre a função da linguagem no contexto da sala de aula.

\section{PROCEDIMENTOS METODOLÓGICOS}

A presente investigação tem natureza qualitativa e, nesse paradigma, buscase, pela constituição, análise e interpretação de dados, compreender o fenômeno investigado. De acordo com Bogdan \& Biklen (1994), em relação à pesquisa qualitativa, pretende-se estabelecer estratégias e procedimentos que possibilitem 
compreender características e significados de fenômenos apresentados do ponto de vista dos participantes da pesquisa. Nesse sentido, a presente investigação visa investigar "como" os professores, da educação básica ou superior, entendem a função da linguagem, no contexto vivenciado em sala de aula.

A coleta de dados foi realizada mediante a aplicação de um questionário aberto, solicitando aos participantes de pesquisa que respondessem a seguinte pergunta: "Que função tem a linguagem na sala de aula de Ciências e Matemática para a aprendizagem?"

A análise das respostas a esse questionamento foi procedida por meio dos procedimentos da Análise Textual Discursiva (ATD), proposta por Moraes e Galiazzi (2011), visando responder à pergunta de pesquisa proposta.

A caracterização dos participantes de pesquisa e dos procedimentos metodológicos da ATD é descrita a seguir.

\subsection{Caracterização dos participantes de pesquisa}

Participaram da pesquisa 20 professores, ingressantes em cursos de mestrado e doutorado em Educação em Ciências e Matemática, de uma Universidade comunitária da região Sul do Brasil. Esses professores atuam na Educação Básica ou no Ensino Superior. Todos os participantes da pesquisa são formados em cursos de graduação, sendo 10 formados na área de Ciências (Ciências, Biologia e Química), seis em Matemática, três em Pedagogia e um em Geografia. A metade dos participantes referiu ter cursado especialização (lato sensu). As idades dos participantes situam-se entre 22 e 47 anos.

Dentre os 20 participantes, cinco afirmaram não ter experiência com docência em sala de aula em regência regular. Quatro deles afirmaram atuar com docência em atividades relacionadas ao PIBID ou em aulas ministradas em laboratórios educacionais. Apenas um informou não ter qualquer experiência de docência em sala de aula.

Oito participantes informaram trabalhar em escolas públicas e seis informaram trabalhar em instituições particulares.

\subsection{A Análise Textual Discursiva}

Moraes e Galiazzi (2011) propõem que sejam considerados quatro focos na organização dos argumentos. O primeiro foco é denominado "desmontagem dos textos”, na qual ocorre a unitariz̧ação do texto, ou seja, fragmentação/codificação em unidades de análise, identificando as principais ideias que respondem à pergunta de pesquisa proposta.

Nesse sentido, as unidades de sentido foram codificadas para possibilitar o retorno ao texto original, se necessário. $\mathrm{Na}$ sequência, as respostas são associadas a uma frase síntese da argumentação, que mostre o significado do que foi escrito para o pesquisador.

O segundo foco é denominado de "estabelecimento de relações", no qual ocorre a "categorização" que consiste em estabelecer relações de semelhança entre as unidades de sentido. A categorização pode ser realizada por meio dos métodos dedutivo ou indutivo. No caso do método dedutivo, as categorias são construídas antes de se 
proceder à análise do corpus da pesquisa, ou seja, do conjunto de textos produzidos pelos participantes. São denominadas de categorias a priori, sendo deduzidas de teorias explícitas já existentes, que servem como fundamento para a pesquisa realizada. No método indutivo as categorias são criadas a partir das unidades de sentido, por meio de comparações e de organização por aproximação ou semelhança, partindo de ideias particulares em direção à ideia geral. Nesse sentido, as categorias emergem da análise realizada pelo pesquisador, considerando seus conhecimentos tácitos ou suas teorias implícitas, que influenciam de modo único suas percepções e interpretações. Nesse caso, as categorias são denominadas de emergentes.

O processo de construção das categorias exige um esforço construtivo intenso e rigoroso, por parte do pesquisador, até que sejam encontradas explicitações claras e convincentes. Não basta caracterizá-las. É necessário que sejam estabelecidas relações entre as ideias presentes nas unidades de sentido. É nesse momento que o pesquisador assume sua função de autor de seus argumentos.

O terceiro foco da ATD é denominado "captar o novo emergente", que consiste na explicitação do "não dito", em torno das categorias criadas. Para isso, são construídos metatextos, por meio dos quais as categorias são descritas e interpretadas, ocorrendo a teorização pelo pesquisador sobre o fenômeno investigado. As categorias e subcategorias são apresentadas, fundamentadas e validadas por meio de relações identificadas, seja por interlocuções empíricas do pesquisador ou por citações diretas das falas dos participantes, retiradas do texto analisado, que fundamentem a argumentação apresentada.

O quarto foco denominado "um processo auto-organizado", consiste na interpretação da ATD, que possibilita compreender novos significados por meio de reflexões a partir dos metatextos.

Assim, a análise compreende em quatro etapas: a "unitarização", ou seja, a desconstrução dos textos do corpus da pesquisa, com a finalidade de se obter as unidades com significado particular para a investigação; a "categorização", que emerge pelo estabelecimento de relações entre as unidades de significado; "o captar o novo emergente", que se obtém por meio de reflexões e de percepções sobre possíveis relações não explícitas, existentes entre categorias inicialmente obtidas; e, finalmente, a "construção de metatextos" que emergem do processo analítico, no qual expressam as interpretações construídas.

No presente artigo foi utilizado o método indutivo, o que resultou em três categorias emergentes, processo que é descrito a seguir.

\section{ANÁLISE DOS RESULTADOS}

A análise das respostas dos participantes da pesquisa, sobre quais seriam seus entendimentos sobre a função da linguagem em sala de aula, possibilitou identificar três categorias emergentes, sendo a função da linguagem percebida pelos professores como: a função da linguagem como meio de comunicação; função da linguagem como meio de aprendizagem; e função da linguagem como meio de formação.

$\mathrm{Na}$ sequência do texto, as falas dos participantes estão apresentadas em itálico, para que se possa dar destaque aos seus argumentos e para que se possa diferenciá-las das citações dos autores. 
Essa categoria foi a que emergiu com maior frequência nas respostas dos participantes. Isso indica uma forte tendência entre os professores, participantes dessa pesquisa, entenderem a função da linguagem como um meio de comunicação entre professor e aluno, conforme o enunciado do Participante 11: "A linguagem é o meio pelo qual o educador se comunica com os educandos.", ou ainda, segundo o Participante 19: “(...) deveriam funcionar como veículos de comunicação entre professor e aluno, especialmente em trabalhos escritos.".

Nesse sentido, em suas respostas os participantes sinalizam que a comunicação seria a principal função da linguagem. Todavia, nas próprias respostas surge a ressalva de que tal função se manifesta de maneiras distintas, conforme se pode observar na resposta do Participante 3 ao afirmar que: "Existem diversas maneiras de se comunicar, seja ela por meio da escrita, leitura, fala e audição.". Esta reflexão está associada à linguagem na perspectiva da ciência semiótica:

[...] quando dizemos linguagem, queremos nos referir a uma gama incrivelmente intrincada de formas sociais de comunicação e de significação que inclui a linguagem verbal articulada, mas absorve também, inclusive, a linguagem dos surdos-mudos, o sistema codificado da moda, da culinária e tantos outros. Enfim: todos os sistemas de produção de sentido aos quais o desenvolvimento dos meios de reprodução de linguagem propiciam hoje uma enorme difusão. (SANTAELLA, 1985, p. 2).

Tal diversificação de manifestação da linguagem, falada ou não falada, auxilia a pessoa a estabelecer relações com o mundo em que vive, possibilitando observar e comunicar fenômenos complexos. A linguagem enquanto meio de comunicação remete a uma das funções básicas, identificadas por Vygotsky (1998), que é a de "intercâmbio social". Para o autor, o desenvolvimento da linguagem é impulsionado pela necessidade de comunicação na "interação social".

Halliday (1993) defende que a linguagem é um recurso para a vida em sociedade. Entende que a maneira de interpretar um contexto de uma situação determina como um indivíduo decide, bem como, o que se decide, influencia em uma situação. Considera um marco decisivo para o desenvolvimento da linguagem, a comunicação de modo interativo e a interpretação da experiência.

Os participantes também argumentam que a linguagem tem a função de ser um meio de comunicação na sala de aula do ensino de Ciências e Matemática, quando se referem ao fato de a linguagem possibilitar: entendimento recíproco; mediação; expressão; descrição; explicação e transmissão de informações.

Como exemplo, foi possível identificar que, no processo de comunicação, a linguagem possibilita o entendimento mútuo, conforme indicado pelo Participante 20: "para que se estabeleça a comunicação é preciso que haja o entendimento recíproco entre quem comunica e quem é comunicado.". Isso se justifica ao se considerar o pensamento complexo, conforme proposto por Edgar Morin (2001). Nessa perspectiva, o autor entende que é fundamental esclarecer que comunicação não subentende compreensão e esclarece que: 
[...] não devemos confundir comunicação e compreensão, porque a comunicação é comunicação de informação às pessoas ou grupos que podem entender o que significa a informação. Mas a compreensão é um fenômeno que mobiliza os poderes subjetivos de simpatia para entender uma pessoa como uma pessoa que é também sujeito. Por exemplo, se eu vejo uma pessoa chorando. Como explicar? Devo fazer uma investigação para chegar à explicação. (MORIN, 2001, p. 42).

Assim, é possível encaminhar reflexão sobre a relação dialógica entre comunicação e compreensão. Além disso, a linguagem como meio de comunicação também pode ser identificada em respostas, nas quais a função da linguagem emerge como mediadora no processo de aprendizagem, que ocorre por meio da comunicação. Essas respostas indicam que, ocorre a interação entre professor, conhecimento e aluno, sendo percebida como mediadora da relação entre educador e educando, por meio do diálogo em sala de aula.

Essas falas e argumentos remetem aos processos de mediação, realizados pela linguagem, idealizados por Vygotsky (1998) e, posteriormente, por Halliday (1993). A linguagem, por permitir a comunicação, também possibilita a interatividade, na atividade social. Assim, a linguagem como sistema simbólico é entendida por Vygotsky (1998) como um "instrumento semiótico", mediador de ações e de atividades mentais, com a função de mediação, na construção de signos. Halliday (1993) considera que a linguagem tem função de mediação simbólica nas interações sociais, pois a considera como um dos sistemas semióticos que constituem uma Cultura, criada como um recurso para a vida em sociedade.

No contexto da sala de aula, quando os participantes referem-se à função da linguagem associada à expressão, emerge que a linguagem possibilita a expressão de conceitos de forma clara e objetiva, conforme indica o Participante 19: " $A$ função da linguagem simbólica consiste em possibilitar expressão dos conceitos científicos criados ao longo da história humana e também dos próprios conbecimentos matemáticos, construidos em sala de aula." Mas também é dito que: "A linguagem possibilita expressar opiniões, pensamentos e sentimentos" (Participante 9). Alguns participantes entendem que uma das funções da linguagem é de descrição de fenômenos enquanto outros afirmam que tem a função de comunicar explicações sobre conceitos e de teorias.

O entendimento de linguagem como fenômeno comunicacional encaminha a uma reflexão complexa de sua abrangência, ampliando noções sobre o termo linguagem, como afirma Santaella (1985, p. 3):

Considerando-se que todo fenômeno de cultura só funciona culturalmente porque é também um fenômeno de comunicação, e considerando-se que esses fenômenos só comunicam porque se estruturam como linguagem, pode-se concluir que todo e qualquer fato cultural, toda e qualquer atividade ou prática social constituem-se como práticas significantes, isto é, práticas de produção de linguagem e de sentido.

A análise também indica que alguns participantes entendem a função da linguagem apenas como meio de transmissão de informações, possibilitando que seja realizada de modo adequado. Um dos participantes afirmou que a função da linguagem seria de exposição de conteúdos e outro afirmou que a função da linguagem seria de transmissão do conhecimento. 
Wells (2001) argumenta que o conhecimento apenas como informação pouco contribui com a compreensão dos estudantes. Para ele é necessário que exista participação ativa na construção colaborativa do conhecimento, para comprovar seus modelos pessoais e, quando seja possível, realizar sua prática na ação. Ressalta a importância do discurso dialógico em sala de aula, permeado por perguntas de interesse dos estudantes que possibilite a troca de informações e a (re)construção dos conhecimentos em sala de aula.

\section{Categoria 2: A função da linguagem como um meio de aprendizagem}

Nessa categoria os participantes responderam que a linguagem tem a função de ser um meio de aprendizagem importante no contexto da sala de aula do ensino de Ciências e Matemática, por: possibilitar a construção de significados e sentidos; influenciar a aprendizagem, em que todos os sentidos são utilizados como meios potencializadores; possibilitar a compreensão do conteúdo, na forma de conceitos científicos e seus significados; auxiliar na interpretação da realidade, possibilitando a contextualização; ser uma ferramenta que possibilita a aprendizagem; e ter função da mediação no processo de aprendizagem.

A função da linguagem como meio de aprendizagem, como potencializadora da construção de significados e sentidos, pode ser identificada na fala do Participante 20, ao afirmar: "Possibilita que consigamos dar significação para o processo de ensinar e aprender". Segundo a perspectiva sociocultural, a linguagem é considerada fundamental para o desenvolvimento humano, pois a aprendizagem ocorre por meio da construção e reconstrução de significados.

Vygotsky (1998) considera que a relação que o homem tem com o mundo não é uma relação direta, mas é mediada por instrumentos e por símbolos, que possibilita o desenvolvimento cognitivo humano. Pesquisar sobre o desenvolvimento cognitivo indica que a constituição dos processos mentais superiores na aprendizagem humana, perpassa por processos de desenvolvimento do pensamento e da linguagem. Assim, toda sua teoria de aprendizagem sociocultural está baseada na linguagem.

Wells (2001) afirma que Vygotsky concebe a linguagem como um "instrumento semiótico", com a função de mediação na construção de signos.

Halliday (1993, p. 93, tradução nossa), ao investigar como a linguagem é utilizada na constituição de sociedades e culturas, afirma:

\footnotetext{
Quando as crianças aprendem a linguagem, elas não estão simplesmente envolvidas em um tipo de aprendizagem entre muitas; ao invés disso, eles estão aprendendo os fundamentos da própria aprendizagem. A característica distintiva da aprendizagem humana é que se trata de um processo de criação de significados: um processo semiótico; e a forma prototípica da semiótica humana é a linguagem. Daí a ontogênese da linguagem é, ao mesmo tempo, a ontogênese de aprendizagem.
}

A análise das respostas também indica que os professores percebem que a linguagem influencia a aprendizagem e que todos os sentidos são utilizados como meios de aprendizagem. Conforme afirma o Participante 20: "Quando estamos envolvidos em aprender algo, nós seres humanos, costumamos canalizar todos os nossos sentidos 
em prol da aprendizagem desejada". Nesse sentido Santaella (2005, p. 2) afirma:

É a tal distração que a aparente dominância da língua provoca em nós que, na maior parte das vezes, não chegamos a tomar consciência de que o nosso estar-no-mundo, como indivíduos sociais que somos, é mediado por uma rede intrincada e plural de linguagem, isto é, que nos comunicamos também através da leitura e/ou produção de formas, volumes, massas, interações de forças, movimentos; que somos também leitores e/ou produtores de dimensões e direções de linhas, traços, cores... Enfim, também nos comunicamos e nos orientamos através de imagens, gráficos, sinais, setas, números, luzes... Através de objetos, sons musicais, gestos, expressões, cheiro e tato, através do olhar, do sentir e do apalpar. Somos uma espécie animal tão complexa quanto são complexas e plurais as linguagens que nos constituem como seres simbólicos, isto é, seres de linguagem.

A função da linguagem como meio de aprendizagem também aparece associada à compreensão de conteúdos, bem como de conceitos científicos e seus significados, aparecendo como facilitadora ou dificultadora da aprendizagem. Conforme o Participante 14: "Os professores precisam trabalhar nomes cientificos da área da Biologia e a própria linguagem cientifica de forma a facilitar a compreensão dos alunos sobre os conteúdos e não o contrário." e o Participante 9 argumenta que: "É a partir da linguagem que conseguimos entender conceitos, definições e explicações de determinadas teorias." Também indicaram a necessidade de que os termos científicos sejam trabalhados adequadamente, de modo a minimizar possíveis dificuldades de aprendizagem, decorrentes da incompreensão de seus significados.

Wells (2001) defende que compreensão difere do conhecimento por ser mais pessoal e imediata, sendo mais holística e intuitiva. A compreensão constitui o momento culminante do conhecer, pois representa o quadro interpretativo em função do qual compreendemos, que leva a uma nova experiência, orientando a ação de modo eficaz e responsável, que gera um novo ciclo do conhecimento. Ainda, defende que a compreensão seria um meio para transformação contínua e deveria ser o objetivo de toda atividade educativa. Sobre isso o Participante 12 afirma que: "A linguagem é a responsável pela compreensão do pensamento.".

Os argumentos relacionados à compreensão, propiciada pela linguagem, também remetem à teoria da linguagem de Halliday (1993), que defende que o desenvolvimento intelectual (ou semiótico) consiste em construções progressivas da gramática, que possibilitam novas maneiras de interpretar a experiência, por meio de reconstruções de significados. Para ele, a criança influenciada pela teoria cultural, constrói novos significados conjuntamente, por meio de intervenções dos adultos. Desse modo, “[...] a adoção de um sistema semiótico linguístico dos adultos torna disponível várias estratégias para ampliar o potencial do significado. [...]" (WELLS, 2001, p.51, tradução nossa).

Wells (2001) afirma que Vygotsky e Halliday indicam que os professores têm um papel fundamental neste processo de abstração, pois reconhecem que cabe ao ensino formal a reconstrução de significados.

A análise também possibilitou identificar, o entendimento dos professores que a linguagem auxilia na interpretação da realidade, o que remete a ideia da linguagem ser um meio para viabilizar a contextualização. O Participante 16 afirma: 
"Cabe ao professor associar a algo que possamos lembrar mais facilmente.", indicando que a tarefa de possibilitar a interpretação seria de responsabilidade do professor. Já o Participante 6 refere: "A matemática, com sua simbologia, auxilia a interpretar, por meio de uma linguagem universal, diferentes relações entre homens e o meio em que vive.".

No contexto sociocultural, Halliday (1993) afirma que a realidade social (ou uma cultura) é um edifício de significados, ou seja, um constructo semiótico. Concebe a linguagem como "semiótica social" e a considera como um dos sistemas semióticos que constituem uma cultura, ou seja, um sistema de informação, que propicia interpretá-la em termos semióticos.

Wells (2001, p.134, tradução nossa) afirma que: ‘[...] na aprendizagem e no emprego da linguagem nos incorporamos e participamos no diálogo continuado de construção de significado das comunidades a que pertencemos."

É possível que essa subcategoria indique que o ensino formal, muitas vezes, não se torna interessante aos estudantes, pois as propostas de ensino estão fragmentadas e descoladas da realidade, logo, descontextualizadas. Assim, os estudantes teriam dificuldades em perceber relações existentes entre o aprendizado teórico e prático, relativos ao meio social e cultural em que vivem, sobretudo em operar em níveis abstratos.

Os professores também identificaram que percebem a função da linguagem como ferramenta para o aprendizado, ao ser utilizada em sala de aula. Conforme afirma o Participante 15: "A linguagem é a ferramenta mais utilizada na sala de aula”. Esse entendimento remete ao conceito de "signos" de Vygotsky, ou seja, são "instrumentos psicológicos" usados no controle das ações psicológicas do indivíduo. Para Oliveira (1993, p. 30): “[...] Na sua forma mais elementar o signo é uma marca externa, que auxilia o homem em tarefas que exigem memória e atenção [...]”.

A linguagem entendida como ferramenta também remete ao conceito de pensamento generalizante de Vygotsky que considera: "[...] a linguagem um instrumento de pensamento: a linguagem fornece os conceitos e as formas de organização do real que constituem a mediação entre o sujeito e o objeto de conhecimento. [...]. “(OLIVEIRA, 1993, p. 43).

Wells (2001) indica que tanto Vygotsky como Halliday entendem que a linguagem se constitui como uma ferramenta de aprendizagem para se alcançar objetivos da vida em sociedade, para compreender realidades, ainda que provisórias.

Para Wertsch (1999, p.121, tradução nossa, grifo do autor), “a linguagem é uma ferramenta cultural e o discurso é uma forma de ação mediada". Assim, no contexto da sala de aula, atuam como ferramenta cultural, associada ao poder e à autoridade, que possibilita comunicação ou o desenvolvimento humano, na ação mediada pelo discurso entre professor e estudantes.

Ainda, nessa subcategoria, o Participante 13 afirma: "Sem a "ferramenta" da linguagem o aprendizado seria muito difuso." Neste sentido, Wells (2001) ressalta a importância da linguagem no desenvolvimento dos diversos tipos de conhecimento, especialmente em relação ao conhecimento teórico, que possibilita a sistematização, por meio da criação de artefatos de conhecimentos permanentes, que permitem resgatar, estudar e revisar os conhecimentos criados. Esses artefatos possibilitam que os conhecimentos culturais e sociais sejam comunicados, fomentando a reconstrução e a criação de novos conhecimentos. 
Halliday (1993) considera o discurso científico como o modo sinóptico de interpretar a experiência, contrastando com o modo dinâmico da conversação informal cotidiana.

Nesta categoria também foi identificada a função da mediação da linguagem na construção do conhecimento. Conforme refere o Participante 12: "A linguagem tem como função a mediação entre a experiência individual do aluno e a construção de seu conbecimento".

Wells (2001) indica que o conhecimento teórico vem da reconstrução do pensamento mediado pela linguagem e pela reflexão da experiência coletiva. Informa que para Vygotsky a linguagem seria “o instrumento dos instrumentos", pois ela funciona como mediadora em atividades sociais e também como instrumento mediador de atividades mentais, associadas ao discurso interno, relativo à fala interior, sendo esse o foco de seus estudos para a compreensão do funcionamento mental humano.

Wells (2001) também afirma que a informação e construção do conhecimento se orientam para o mundo social da interação discursiva, no qual os significados e as representações públicas são mediados por representações semióticas.

Além disso, um dos participantes afirma que a linguagem "possibilita a troca de conhecimentos" (Participante 18).

Segundo Wells (2001), o conhecimento não pode ser trocado simplesmente, pelo fato de não estar presente em artefatos concretos, como livros, ou até mesmo no próprio sujeito, pois não é estático, mas está em contínua reconstrução, sendo modificado por interações sociais, em atos que promovem o conhecimento. Nesse sentido, o argumento utiliza o termo "conhecimento" de modo inadequado.

Categoria 3: A função da linguagem como um meio para formação, na construção de conhecimentos.

Esta categoria emergiu dos argumentos dos professores quando se referiram ao fato da linguagem: possibilitar a formação crítica e o desenvolvimento cognitivo; possibilitar a alfabetização científica; possibilitar o registro dos conceitos científicos; propiciar a adequação ao grau de conhecimento do aluno; e possibilitar a especialização do conhecimento.

Conforme indica o Participante 12, a linguagem proporciona “[...] 0 pensamento crítico dos alunos, papel primordial do desenvolvimento intelectual do aluno. [...] é o mecanismo fundamental para o desenvolvimento cognitivo [...]." .

Essa fala remete à teoria de Vygotsky (1998, p. 62): “[...] o desenvolvimento do pensamento é determinado pela linguagem, isto é, pelos instrumentos linguísticos do pensamento e pela experiência sócio-cultural da criança.”. Além disso, ao apresentar sua teoria sobre o desenvolvimento das funções mentais superiores, argumentou que a atividade mental adulta não é apenas resultado da experiência individual e da maturação, mas que é transformada e enriquecida por assimilações das experiências da humanidade, mediante o emprego de instrumentos semióticos em ação ocorridos por meio da interação social.

Halliday (1993, p. 102, tradução nossa) indica que "[...] o aprendizado torna-se um processo semiótico de dois sentidos, baseado na reciprocidade de 
aprendizagem e ensino. [...]". A passagem para a escola e as exigências da alfabetização marcam a passagem do concreto ao abstrato, o que Halliday caracteriza como processo de "abstração", quando as crianças começam a perceber a linguagem como um instrumento semiótico, que tem sua própria estrutura e organização.

Tanto Vygotsky, quanto Halliday reconhecem que o ensino formal (escolar) influencia, consideravelmente, o desenvolvimento intelectual e a reconstrução de significados (WELLS, 2001).

Em relação ao desenvolvimento do pensamento crítico, Freire e Faundez (1998, p. 26) afirmam que: “[...] a origem do conhecimento está na pergunta, ou nas perguntas, ou no ato mesmo de perguntar; [...]”. Com relação a isso, pode-se, ainda, afirmar que a formação crítica por meio da linguagem é essencial para que se estabeleça o conhecimento, bem como o pensamento crítico. Nesse sentido, a pergunta seria o elemento que daria vazão à dúvida, pois não se pode pensar em criticidade se não possibilitarmos a dúvida sobre o que se está levando a conhecer pelo outro. Quando há a compreensão por parte do indivíduo, esse estabelece relações, ressignificando o expressado, a ponto de poder, a partir da reflexão e do questionamento, reconstruir conceitos, construindo sua aprendizagem de maneira crítica. Paulo Freire (1993, p. 266) ainda afirma que:

Em primeiro lugar, a oralidade precede a grafia, mas traz em si desde o primeiro momento em que os seres humanos se tornaram socialmente capazes de ir exprimindo-se através de símbolos que dizia algo de seus sonhos, de seus medos, de sua experiência social, de suas esperanças, de suas práticas.

Em relação a isso o Participante 9, afirma: "A função da linguagem é possibilitar interpretações do mundo ao seu redor." Pode-se, a partir dessa ideia, entender que a oralidade diz do mundo antes mesmo da grafia. E é por meio dela que expressamos, na maior parte do tempo, nossos pensamentos, o que justifica o diálogo e a reflexão em torno do entendimento de algo, na busca constante de sua compreensão. Desse modo possibilita, por meio da linguagem, a formação crítica.

Pedreira e Bargalló (2011) salientam que é possível construir significados para os conceitos científicos por meio da conversa, dando sentido à aprendizagem escolar. Argumentam que a conversa no ambiente possibilita a mudança real em suas formas de pensar e não apenas mudanças superficiais, desconectadas de suas realidades. Desse modo, afirmam: "Se aceitarmos que vivemos em um mundo complexo, temos de aceitar que falar ajuda a entender, e que dá sentido aos conceitos e fenômenos que têm laços inseparáveis a outros conceitos e fenômenos." (PEDREIRA e BARGALLÓ, 2011, p. 33, tradução nossa)

Nesta categoria, os argumentos dos participantes também indicam que a linguagem é importante na sala de aula, pois esse é o ambiente de alfabetização dos estudantes. Conforme o enunciado do Participante 4: "A função da linguagem na sala de aula de Ciências e Matemática é importante, pois é o ambiente de alfabetizar cientificamente o individuo.".

Segundo Chassot (2003, p. 91):

[...] A ciência pode ser considerada como uma linguagem construída pelos homens e pelas 
mulheres para explicar o nosso mundo natural. (...) ser alfabetizado cientificamente é saber ler a linguagem em que está escrita a natureza. É um analfabeto científico aquele incapaz de uma leitura do universo.

Nesse sentido, a linguagem teria a função de possibilitar aos estudantes a reconstrução de conhecimentos cotidianos, que os possibilitassem compreender o mundo onde vivem.

Também afirmaram que a linguagem tem a função de possibilitar a elaboração de registros de conceitos científicos já existentes e construídos em sala de aula. Conforme refere o Participante 19: "A função da linguagem simbólica consiste em possibilitar registro dos conceitos científicos criados ao longo da história bumana e também dos próprios conhecimentos matemáticos, construídos em sala de aula."

$\mathrm{Na}$ teoria da aprendizagem interacionista de Vygotsky, o processo formativo do funcionamento psicológico não é inato, mas ocorre ao longo da vida. Sua teoria também considera que as funções psicológicas superiores são produtos da atividade cerebral e têm suporte biológico; as relações sociais do indivíduo com o mundo, que se desenvolvem em processos históricos, fundamentam o funcionamento psicológico humano e que os sistemas simbólicos sendo mediados por sistemas simbólicos são mediadores da relação do homem com o mundo (VYGOTSKY, 1998).

Nessa categoria, os participantes também entendem que a linguagem deve ser adequada para possibilitar a transmissão da informação, de acordo com o grau de conhecimento do aluno, conforme afirma o Participante 11: "Os conceitos e termos científicos que devem ser apresentados ou introduzidos aos alunos de forma adequada.".

Acredita-se que esse argumento se refira à importância do discurso dialogado em sala de aula, de modo que possibilite, pelo entendimento recíproco, a construção de conhecimentos acadêmicos.

Segundo Bargalló (2005), para aprender ciências, por meio da linguagem, faz-se necessário desenvolver a competência comunicativa cientifica, de modo que os alunos a aprendam primeiro como um sistema interpretativo e depois como um sistema de rotulagem. Indica que muitas dificuldades de professores e estudantes estão no fato de usarem a linguagem apenas como um sistema de rotulagem. Isso leva à percepção incorreta de que os conhecimentos científicos seriam estáticos. Sugere que os professores propiciem atividades que possibilitem perceber e desenvolver o sistema interpretativo, para perceberem o caráter dinâmico da ciência. Afirma que a leitura autônoma e significativa de textos está relacionada ao desenvolvimento da competência comunicativa cientifica, possibilitando ao estudante melhorar suas formas de ler, escrever e falar sobre ciências, o que certamente contribuam para aprimorar seus conhecimentos.

Nessa categoria também emergiu a ideia de que a linguagem possibilita a especialização do conhecimento, conforme o enunciado do Participante 13: "Sem a linguagem não teríamos a capacidade de aprofundarmos em alguns conhecimentos.". Sobre isso, Maturana (1997), afirma que, com o convívio interativo com outros, criamos nosso mundo pela linguagem, o que nos permite perceber outras perspectivas, afastando-nos de certezas pessoais absolutas. Segundo ele:

Pela linguagem emerge a experiência do mental e a consciência humana como expressão do centro mais íntimo do homem; ao situá-lo no plano da coordenação das interações 
recorrentes junto a outros, despoja-se o indivíduo de toda certeza absoluta do pessoal e se o convida para situar-se em uma perspectiva mais ampla: a criação de um mundo junto com os outros. (MATURANA, 1997, p. xviii, tradução nossa).

Além disso, afirma que a linguagem nos constitui enquanto seres humanos, pois:

[...] os objetos, a consciência, a auto-reflexão, o ser, a natureza, a realidade, tudo o que como seres humanos fazemos e somos se concretiza na linguagem porque utilizamos a linguagem para gerá-los, não como mera abstração ou discurso, mas tão concretos como qualquer operação no fluxo das coordenações consensuais de ações nas quais surgimos e existimos" (Ibid, p. 96, tradução nossa).

\section{CONSIDERACְ̃̃ES FINAIS}

A análise realizada na presente investigação possibilitou identificar três categorias emergentes finais, sendo a função da linguagem entendida pelos professores como: meio de aprendizagem; meio de comunicação e como meio para formação, que remetem às compreensões consideradas sobre linguagem dos autores apresentados. No entanto, apesar de identificá-las por meio da ATD, percebe-se que as três categorias citadas não estão simultaneamente presentes nos entendimentos de todos os professores. Isso leva a inferir que a pouca reflexão e a valorização da linguagem, no contexto da sala de aula, podem fazer com que os professores não explorem suas ferramentas como meios para potencializar as competências dos estudantes, para uma leitura/expressão de mundo, o que pode prejudicar suas aprendizagens escolares, na (re)construção e significação de seus conhecimentos.

Também se observou que, na fala dos participantes, identificam-se teorias que dizem respeito ao conceito da linguagem. No entanto, nenhum participante expressou estar conceituando a linguagem segundo um autor específico. Isso demonstra que sempre quando se fala sobre algum assunto, ou situação, ou objeto, se infere a estes algum conhecimento, já expresso anteriormente, ou seja, já possuímos algum conceito formado e muito particular "sobre". E isso se dá por meio das várias interpretações, que foram sendo construídas ao longo da vida e das linguagens pelas quais nos constituímos.

O trabalho de investigação não se encerra, mas pode a partir de outras pesquisas possibilitar novas interpretações para o problema identificado, tais como compreender as percepções sobre dificuldades em relação ao uso da linguagem em sala de aula, bem como analisar de que modo os professores entendem as relações da linguagem como o processo de aprendizagem dos alunos.

\section{REFERÊNCIAS}

BOGDAN, R. C.; BIKLEN, S. K. Investigação qualitativa em educação. Porto: Porto Editora, 1994.

BARGALLÓ, C. M. Aprender ciencias a través del linguaje. Educar. México, n. 33, abr/jun, p. 27-38. 2005.

CHASSOT, A. Alfabetização científica: uma possibilidade para a inclusão social. Revista brasileira de educação. n. 22. jan./fev./mar./abr, p.89-100. 2003. 
FREIRE, P. Pedagogia da esperança: um reencontro com a Pedagogia do oprimido. Rio de Janeiro: Paz e Terra, 1992.

FREIRE, P. Professora sim, tia não: cartas a quem ousa ensinar. São Paulo: Olho d’ Água, 1993.

FREIRE, P.; FAUNDEZ, A. Por uma pedagogia da pergunta. $4^{a}$ ed. Rio de Janeiro: Paz e Terra, 1998.

HALLIDAY, M.A.K. Towards a Language-Based Theory of Learning. Linguistics and Education, v. 5, p. 93- 116, 1993.

HALLIDAY, M.A.K. Language as social semiotic: the social interpretation of language and meaning. Londres: Edward Arnold, 1978.

HALLIDAY, M.A.K. Introduction to functional grammar. Edward Arnold: London, 1985.

HALLIDAY, M.A.K.; MATTHIESSEN, C.M.I.M. An Introduction to Functional Grammar, 3, ed. London: Edward Arnold, 2004

MARTINS, O.; MOSER, A. Conceito de mediação em Vygotsky, Leontiev e Wertsch. In: Intersaberes, v.7, n.13, p.8-28, 2012.

MATURANA, H. R. La Realidad: objetiva o construída? Barcelona: Anthropos, 1997.

MORAES, R.; GALIAZZI, M. C. Análise textual discursiva. 2a ed. rev. Ijuí: Ed. Unijuí, 2011.

MORIN, E. As duas Globalizações: complexidade e comunicação, uma pedagogia do presente. Porto Alegre: Sulina, 2001.

MORIN, E. Da necessidade de um pensamento complexo. In: Para Navegar no Século XXI. Org. Francisco Menezes Martins e Juremir Machado da Silva. 3. ed. Porto Alegre: Sulina, EDIPUCRS, 2003.

OLIVEIRA, M. K. Aprendizado e desenvolvimento um processo sócio-histórico. São Paulo: Scipione, 1993.

PEDREIRA, M.; BARGALLÓ, C. M. Per què insistim a conversar per aprendre ciències? Revista de didàctica de la llengua i de la literatura. n. 54, p. 29-36. Abr.2011.

PEIRCE, C.S. Semiótica e filosofia. São Paulo: Cultrix, 1972.

SANTAELLA, L. O que é semiótica. São Paulo: Editora Brasiliense, $2^{a}$ ed., 2005.

VYGOTSKY, L. S. Pensamento e linguagem. Tradução Jefferson Luiz Camargo. 2. ed. São Paulo: Martins Fontes, 1998.

WELLS, G. Indagación dialógica: hacia uma teoria y uma práctica socioculturales de la educación. Buenos Aires: Paidós, 2001.

WERTSCH, J. V. La mente en acción. Buenos Aires: Aique, 1999.

Submetido em 29/03/2016

Aprovado em 15/11/2017

\section{Contato:}

Rosana Maria Luvezute Kripka

Instituto de Ciências Exatas e Geociências, Universidade de Passo Fundo

CAMPUS I - BR 285, Bairro São José

CEP 99.052-900 - Passo Fundo, RS - Brasil 